\title{
Níveis de suplementação na terminação de novilhos Nelore em pastagens: aspectos econômicos
}

\author{
Robério Rodrigues Silva ${ }^{1}$, Ivanor Nunes do Prado², Gleidson Giordano Pinto de Carvalho4, \\ Fabiano Ferreira da Silva ${ }^{1}$, Vitor Visintin Silva de Almeida ${ }^{4}$, Hermógenes Almeida de \\ Santana Júnior ${ }^{1}$, Mônica Lopes Paixão ${ }^{1}$, George Abreu Filho ${ }^{1}$
}

\footnotetext{
1 Universidade Estadual do Sudoeste da Bahia, CEP: 45700-000, Itapetinga, BA.

2 Universidade Estadual de Maringá, CEP: 87020-900, Maringá, PR.

3 Universidade Federal da Bahia, CEP: 40170-110, Salvador, BA.

${ }^{4}$ Universidade Federal de Viçosa, CEP: 36571-000, Viçosa, MG.
}

RESUMO - Objetivou-se avaliar as respostas econômicas de novilhos Nelore em terminação à suplementação em pastagens de Brachiaria brizantha no Sudoeste da Bahia. O experimento foi desenvolvido no período de agosto a novembro de 2006 em uma área de 52,0 hectares, dividida em oito piquetes de aproximadamente 6,5 hectares. Testaram-se quatro níveis de suplementação com concentrado (controle, 0,3; 0,6 e 0,9\% do peso vivo do animal) em comparação à suplementação com sal mineral. Os níveis de suplementação elevaram a quantidade de carne produzida por hectare. A curva de crescimento da receita é menos acentuada que a dos custos, o que resulta em achatamento do lucro de acordo com os níveis de suplementação estudados. Os melhores resultados biológicos obtidos com elevados níveis de suplemento não são economicamente sustentáveis, em decorrência do aumento do custo de produção, no entanto, níveis de suplementação inferiores a 0,3\% do peso vivo na fase de terminação são viáveis e têm potencial econômico.

Palavras-chave: Brachiaria brizantha, produção de carne, sistemas de produção de bovinos

\section{Supplementation levels in finishing of Nelore steers on pastures: economic aspects}

ABSTRACT - In this study, it was aimed to evaluate the economic responses of finishing Nellore steers to supplementation of Brachiaria brizantha pastures in southwestern Bahia. The experiment was developed from August to November 2006 in a 52-ha area divided in eight pickets of approximately 6.5 hectares each. It was tested four levels of concentrate supplementation (control, $0.3,0.6$ and $0.9 \%$ of the body weight of animal) compared to supplementation with mineral salt. Supplementation levels raised the amount of meat produced per hectare. The curve of revenue growth is less sharp than the cost growth curve, resulting in a flattening of profit according to levels of the studied supplementation. The best biological results obtained from high levels of supplements are not economically sustainable because of the increase in the production cost, however, supplementation levels lower than $0.3 \%$ of body weight in the finishing phase are feasible and they are potentially economical.

Key Words: Brachiaria brizantha, meat production, production systems of cattle

\section{Introdução}

A cada ano que passa, o agronegócio brasileiro consolida sua importante posição na economia, como resultado do avanço tecnológico, do incremento na produtividade e da ocupação de novas áreas (Fernandes et al., 2007). Desta maneira, como qualquer atividade do setor pecuário, para se manter competitiva, deve ser constantemente avaliada, principalmente no que tange aos aspectos econômicos. Neste contexto, os custos de produção da atividade, a receita obtida e a rentabilidade do capital investido são fatores importantes para o sucesso de qualquer sistema de produção.
A produção de carne no Brasil tem crescido significativamente, observando-se que, a partir de 1990, com a globalização da economia e a abertura dos mercados, intensificou-se ainda mais o processo de modernização da atividade agropecuária, em decorrência do aumento da competitividade e da forte pressão da relação desfavorável entre os preços de insumos e de produtos (Fernandes et al., 2007). Contudo, as dificuldades para abater animais jovens ainda persistem nas condições brasileiras (Jorge et al., 1997), uma vez que os estudos de peso de abate citados demonstraram que o manejo dos animais visava o abate entre 24 e 30 meses de idade. No atual contexto econômico, verifica-se interesse crescente em estratégias que proporcionem melhores 
resultados de eficiência produtiva e qualidade dos produtos, pois a atividade pecuária tende a ser mais uma atividade empresarial, afastando-se do modelo extrativista e aproximando-se da intensificação total (Euclides Filho, 2004).

Existem duas formas básicas de interferir no ganho financeiro real de uma atividade: aumentando seu preço de venda, mas com algumas consequências em relação à demanda, ou implementando uma política de redução de custos e aumento de produtividade, que também favoreceria o aumento da margem sem, contudo, depender diretamente do fator demanda (Figueiredo et al., 2007). Enquanto a viabilidade técnica da suplementação de animais em pastejo é considerada praticamente consolidada, questionamentos quanto à sua viabilidade econômica existem desde longa data, muito embora comparações econômicas entre os sistemas intensivos e extensivos de pecuária tenham apontado para resultados superiores para os sistemas intensivos (Pilau et al., 2003).

Neste estudo objetivou-se avaliar as respostas econômicas de quatro níveis de suplementação na terminação de novilhos Nelore em pastagens de Brachiaria brizantha no sudoeste da Bahia.

\section{Material e Métodos}

O experimento foi desenvolvido na Fazenda Boa Vista, localizada no município de Macaraní, estado da Bahia, no período de 12 de agosto a 18 de novembro de 2006. A parte de campo foi implantada numa área de 52,0 hectares, dividida em oito piquetes de aproximadamente 6,5 hectares cada, formada de Brachiaria brizantha, cultivar Marandu, subdivididas em formato de setores (formato de pizza) com aguada central. As análises laboratoriais foram realizadas no Laboratório de Análise de Alimentos do Departamento de Química da Universidade Estadual de Maringá - UEM e no Laboratório de Nutrição Animal do Departamento de Tecnologia Rural e Animal da Universidade Estadual do Sudoeste da Bahia - UESB. O Projeto foi financiado pelo Fundo de Apoio ao Desenvolvimento Científico e Tecnológico (FUNDECI) do Bando do Nordeste do Brasil (BNB).

Foram utilizados 40 novilhos da raça Nelore com $371,00 \pm 14,0 \mathrm{~kg}$ e 26 meses de idade distribuídos em delineamento inteiramente casualizado com quatro níveis de suplementação com concentrado (controle, 0,3; 0,6 ou 0,9\% do peso vivo), em comparação à suplementação com sal mineral, avaliados dez repetições. Os concentrados foram formulados segundo o NRC (2000), visando obter ganhos de 0,350; 0,650 e 0,850 kg. O período experimental total foi de 98 dias, de modo que 14 deles foram de adaptação dos animais.
A pastagem foi avaliada a cada 28 dias. Para estimar a disponibilidade de MS de cada piquete, foram tomadas 12 amostras cortadas ao nível do solo com um quadrado de $0,25 \mathrm{~m}^{2}$, conforme metodologia descrita por McMeniman (1997). Foi adotado o método de lotação contínua com mesma carga animal. Foram utilizados oito piquetes, diferidos no início de maio. Para reduzir a influência da variação de biomassa entre piquetes, os novilhos permaneceram em cada piquete por sete dias e, após esse período, foram transferidos para outro, em um sentido pré-estabelecido de forma aleatória.

As estimativas de biomassa residual diária de matéria seca foram realizadas nos quatro piquetes, conforme o método da dupla amostragem (Wilm et al., 1994). Utilizando-se os valores das amostras cortadas e estimadas visualmente, foi calculada a biomassa de forragem expressa em $\mathrm{kg} / \mathrm{ha}$ pela equação proposta por Gardner (1986).

A estimativa da taxa de acúmulo diário de MS (TAD) foi realizada por meio da equação proposta por Campbell (1966), sendo que os quatro piquetes que permaneciam vedados por 28 dias funcionaram como gaiolas de exclusão. A taxa de lotação (TL) foi calculada considerando a unidade animal como de $450 \mathrm{~kg}$ de PV.

A oferta de forragem (OF) foi calculada de acordo com a seguinte fórmula:

$$
\mathrm{OF}=\left\{(\mathrm{BRD} * \text { área }+\mathrm{TAD} * \text { área }) / \mathrm{PV}_{\text {total }}\right\} * 100
$$

em que: $\mathrm{OF}=$ oferta de forragem, em kg MS/100 kg PV/dia; $\mathrm{BRD}=$ biomassa residual diária, em kg de MS/ha/dia; $\mathrm{TAD}$ = taxa de acúmulo diário, em kg MS/ ha/dia; PV = peso vivo dos animais, em $\mathrm{kg} / \mathrm{ha}$.

Os animais foram pesados no início e no final do experimento, além de pesagens intermediárias a cada 28 dias, para avaliação do ganho médio diário (GMD) e ajuste do fornecimento do suplemento. As pesagens foram precedidas por jejum alimentar de $12 \mathrm{~h}$.

O concentrado (Tabela 1) foi fornecido em grupo, todos os dias às $10 \mathrm{~h}$, em cochos plásticos sem cobertura com 9,60 m lineares, para evitar a competição por espaço entre os animais. As sobras, quando houve, foram mensuradas diariamente.

Para estimar a produção fecal, utilizou-se o óxido crômico como indicador externo, fornecido diariamente às 9 h, em dose única de 10,0 g, durante 12 dias, sendo sete dias para adaptação e regulação do fluxo de excreção do marcador e cinco dias para coleta das fezes. As fezes foram coletadas uma vez ao dia, no momento da administração do indicador, diretamente da ampola retal, e armazenadas em câmara fria a $-10^{\circ} \mathrm{C}$. As amostras de fezes foram analisadas por espectrofotometria de absorção atômica (EAA) para dosagem de cromo, conforme Williams et al. (1962). 
Tabela 1 - Composição química da Brachiaria brizantha e dos concentrados (\%) na base da matéria seca

\begin{tabular}{|c|c|c|c|c|}
\hline Item & Capim-braquiária seco & \multicolumn{3}{|c|}{ Nível de suplementação (\% do peso vivo) } \\
\hline Fubá de milho & - & 89,98 & 95,11 & 87,98 \\
\hline Ureia & - & 5,00 & 2,44 & 0,06 \\
\hline Sal mineral ${ }^{1}$ & 100 & 5,02 & 2,45 & 1,56 \\
\hline Proteína bruta (\%) & 6,09 & 22,49 & 15,61 & 13,30 \\
\hline Extrato etéreo (\%) & 2,20 & 3,61 & 3,73 & 3,92 \\
\hline Carboidratos totais (\%) & 85,61 & 68,02 & 77,30 & 80,04 \\
\hline Carboidratos não-fibrosos (\%) & 1,31 & 55,78 & 64,37 & 66,68 \\
\hline Fibra em detergente neutro (\%) & 84,30 & 12,24 & 12,93 & 13,36 \\
\hline Fibra em detergente ácido (\%) & 46,00 & 4,14 & 4,38 & 5,12 \\
\hline Disponibilidade total de MS (kg/ha) & 3654,84 & - & - & - \\
\hline Biomassa residual (kg de MS/ha/dia) & 130,53 & - & - & - \\
\hline Taxa de lotação (UA/ha) & 0,73 & - & - & - \\
\hline Taxa de acúmulo diário (kg MS/ha/dia) & 40,83 & - & - & - \\
\hline Oferta de forragem (kg MS/100 kg PV/dia) & 26,60 & - & - & - \\
\hline \multicolumn{5}{|l|}{ Consumo de alimentos } \\
\hline Consumo de matéria seca total (kg/dia) & 7,41 & 8,61 & 7,54 & 8,10 \\
\hline Consumo de matéria do pasto (kg/dia) & 7,41 & 7,46 & 5,24 & 4,65 \\
\hline Consumo de matéria do total (\%, PV) & 1,91 & 2,17 & 1,90 & 2,02 \\
\hline \multicolumn{5}{|l|}{ Desempenho animal } \\
\hline
\end{tabular}

${ }^{1}$ Composição: Ca - 13,2\%; P - 4,4\%; Mg - 0,5\%; S - 1,2\%; Na - 17,8\%; Se - 0,0012\%; Cu - 0,125\%; Zn - 0,03\%; Mn - 0,075\%; I - 0,005\%; Co - 1,07\%.

Para determinação do indicador interno, fibra em detergente ácido indigestível (FDAi), as amostras da forragem, das fezes e dos concentrados foram incubadas no rúmen de quatro animais fistulados por 144 horas, assumindo o resíduo como indigestível.

A digestibilidade aparente (parcial e total) e o consumo de matéria seca foram estimados a partir da produção fecal, utilizando-se óxido crômico $\left(\mathrm{Cr}_{2} \mathrm{O}_{3}\right)$ como indicador externo e da fibra em detergente ácido indigestível (FDAi) como indicador interno.

Os sistemas de produção foram diferenciados pelo nível de suplementação, ganho de peso diferenciado pelos índices tecnológicos que serviram para a estruturação dos modelos (níveis de suplementação). A construção das curvas de crescimento dos animais e das posteriores análises de viabilidade econômica foram realizadas após a coleta dos dados e avaliação do desempenho produtivo biológico do experimento, sobretudo os consumos de suplemento e os ganhos de peso médios diários referentes aos quatro tratamentos.
Os indicadores da viabilidade econômica dos níveis de suplementação analisados foram: peso vivo inicial (em kg); peso vivo final (em kg); idade inicial dos animais; área de pastagens por tratamento; ganho médio diário (g); consumo de concentrado; consumo de sal mineral; preço dos concentrados e do suplemento mineral; número de animais; peso médio no período (média entre peso vivo final e peso vivo inicial, em kg); peso médio, em UA/cabeça (peso médio no período dividido por $450 \mathrm{~kg}$, que equivale a 1,00 UA); taxa de lotação, em UA/ha (peso médio em UA/cabeça multiplicado pelo número de animais e dividido pela área de pastagem, em hectares); ganho médio diário (média ponderada da fase de suplementação, 84 dias, com do período das águas, de 100 dias); produção em kg PV/ha/84 dias (peso vivo final, em kg, menos o peso vivo inicial, multiplicado pelo número de animais e dividido pela área da pastagem, em hectares); rendimento de carcaça (obtido junto ao frigorífico BERTIN - Itapetinga para animais de mesmo padrão genético); produção de carne (kg PV/ha/ano multiplicado pelo rendimento de carcaça); produção de 
carne (@/hectare/84 dias); consumo de concentrado (consumo de concentrado ou sal mineral por animal/dia multiplicado pelos 10 animais de cada grupo e pelos 84 dias do período de suplementação dividido pelos 13 hectares de pastagem); consumo de mineral (no grupo que recebeu sal mineral, foi o consumo diário multiplicado pelos 84 dias do ano, enquanto no grupo sob suplementação o sal mineral foi incluído no concentrado); custo do concentrado (consumo, em kg/ha/84 dias, multiplicado pelo preço, kg, histórico (2001-2006) na região); custo de suplemento mineral (consumo de suplemento mineral, kg/hectare/ano, multiplicado pelo preço, kg, histórico (2001-2006) na região); custo com concentrado (custo do concentrado, em $\mathrm{R} \$ / \mathrm{ha} /$ 84 dias, dividido pela produção de carne, em @/ha/ano); custo com suplemento mineral (em R $\$$ /ha/84 dias dividido pela produção de carne, em @/ha/ano); mão-de-obra, combustíveis; medicamentos, manutenção de cercas, manutenção de pastos e impostos (em R\$ por @, obtidos no ANUALPEC, 2006); custo total por @ produzida (custo com concentrado + custo com suplemento mineral + mãode-obra + combustíveis + medicamentos + manutenção de cercas + manutenção de pastos + impostos, em R\$/@); preço médio da carne (média histórica de preços da @ de boi gordo no estado da Bahia entre 2001 e 2006 para o mês de novembro (ANUALPEC (2006)); renda bruta (preço médio da carne vendida, em $\mathrm{R} \$ / @$, multiplicado pela produção, @/ha/84 dias); renda bruta por animal/84 dias (renda bruta, em R\$, por hectare/84 dias multiplicada pelo resultado da divisão da área utilizada pelos animais que a ocuparam); renda bruta por tratamento/84 dias (renda bruta, em $\mathrm{R} \$ / \mathrm{ha} / 84$ dias, multiplicada pela área total); custo total da produção de carne (em R\$/@ produzida multiplicado pela produção por hectare/84 dias); saldo por hectare/84 dias (renda bruta/ha/84 dias menos o custo total por hectare/84 dias, em R\$); preço de aquisição da @ do boi magro (valor médio no período de 2001 a 2005, conforme o ANUALPEC (2006)); compra do boi magro, em R\$, por hectare/84 dias (preço da @ do boi magro multiplicado pela quantidade de @ iniciais de cada animal multiplicado pelo número de animais e dividido pela área de pastagem em cada grupo); capital investido por hectare/ 84 dias (somatório do custo total, em $\mathrm{R} \$ / \mathrm{ha} / 84$ dias + compra do boi magro, em $\mathrm{R} \$ / \mathrm{ha} / 84$ dias); retorno da aplicação na caderneta de poupança com taxa líquida de $4,00 \%$ ao ano (capital investido, em $\mathrm{R} \$ / \mathrm{ha} / 84$ dias, multiplicado por 4,00\%); retorno anual da atividade, em \% (saldo em $\mathrm{R} \$ / \mathrm{ha} / 84$ dias dividido pelo capital investido, sem o custo da terra, multiplicado por 100).

Os dados econômico-financeiros e dos custos de produção em diferentes sistemas de suplementação foram analisados estatisticamente por meio de análise de variância e regressão a $5 \%$ de probabilidade.

\section{Resultados e Discussão}

A suplementação mineral, quando comparada às demais estratégias de terminação, promoveu menor ganho $(\mathrm{P}<0,05)$ médio diário aos animais podendo comprometer o ciclo de produção. Entretanto, os ganhos médios apresentaram resposta linear crescente $(\mathrm{P}<0,05)$ aos níveis de concentrado, provavelmente em razão das chuvas atípicas no período de agosto a novembro de 2006 (Tabela 2), que resultaram em alta disponibilidade de matéria seca, com grande quantidade de folhas verdes, permitindo aos animais exercer o pastejo seletivo com consumo de forragem de melhor valor nutricional. Esse fato, favorável aos níveis de suplementação com sal mineral e com concentrado no nível de $0,3 \%$ do PV, não teve o mesmo efeito nos grupos com suplementação nos níveis de 0,6 e $0,9 \%$ do peso vivo (Tabela 3 ).

O fornecimento do suplemento concentrado pode levar a um efeito associativo, mudando o desaparecimento da FDN no rúmen, tanto positiva como negativamente. De acordo com Silva et al. (2009), em extensa revisão sobre suplementação durante a época seca, níveis acima de 0,2 - 0,3\% do peso vivo em oferta de suplemento, já seriam suficientes para que ocorresse efeito substitutivo da pastagem pelo suplemento. Neste estudo ficou evidente a substituição da forragem pelo concentrado e não alcançando os ganhos esperados de 650 e 850 g nos níveis de 0,6 e 0,9\% do PV, respectivamente. Mesmo que não tenha sido desejável, o resultado obtido com a suplementação no nível de 0,9\% comprovou efeito linear crescente $(\mathrm{P}<0,05)$ da suplementação, pois foi $240,48 \mathrm{~g}$ superior ao observado no grupo que recebeu sal mineral e 133,40 e 98,76 g superior aos obtidos com concentrado nos níveis de 0,3 e 0,9\% do PV. Essa intensificação do processo de produção promoveu aumento linear $(\mathrm{P}<0,05)$ de $60,12 \%$ na produção em kg de peso vivo por hectare nos 84 dias em relação ao valor obtido sem suplementação; de 26,29\% e $18,23 \%$ em relação ao observado com o fornecimento de concentrado nos níveis de 0,3 e $0,6 \%$ do PV. Os valores esperados eram, respectivamente, 142,86 e 30,77\% nos níveis de 0,3 e $0,6 \%$ do PV.

Tabela 2 - Umidade relativa do ar, temperatura, precipitação e ponto de orvalho $\left({ }^{\circ} \mathrm{C}\right)$ na área experimental

\begin{tabular}{lc}
\hline Item & $(12 / 8 / 2006$ a $18 / 11 / 2006)$ \\
\hline Umidade relativa do ar (\%) & 78,54 \\
Temperatura $\left({ }^{\circ} \mathrm{C}\right)$ & 23,23 \\
Precipitação $(\mathrm{mm})$ & 155,90 \\
Ponto de orvalho $\left({ }^{\circ} \mathrm{C}\right)$ & 18,86 \\
\hline
\end{tabular}


Tabela 3 - Indicadores zootécnicos e de tamanho utilizados na estruturação dos modelos que caracterizaram os níveis de suplementação testados

\begin{tabular}{|c|c|c|c|c|}
\hline & \multirow[t]{2}{*}{ Sal mineral } & \multicolumn{3}{|c|}{ Nível de concentrado (\% do peso vivo) } \\
\hline & & $0,3 \%$ & $0,6 \%$ & $0,9 \%$ \\
\hline Idade inicial (meses) & 26 & 26 & 26 & 26 \\
\hline Peso vivo final em $\mathrm{kg}^{1}$ & 404,60 & 413,60 & 416,50 & 424,80 \\
\hline Peso médio no período, kg $((1+2) /(2))$ & 387,80 & 392,30 & 393,75 & 397,90 \\
\hline Peso médio (UA/cabeça) (3/(450)) & 0,86 & 0,87 & 0,88 & 0,88 \\
\hline Número de animais & 10 & 10 & 10 & 10 \\
\hline Ganho médio diário (84 dias), $\mathrm{g}^{2}$ & 400,00 & 507,14 & 541,72 & 640,48 \\
\hline Produção, kg de PV/ha/84 dias $\left((2-1)^{*} 7 / 5^{*} 13\right)^{3}$ & 33,60 & 42,60 & 45,50 & 53,80 \\
\hline Rendimento de carcaça (\%) & 53,00 & 53,00 & 53,00 & 53,00 \\
\hline Produção de carne, kg/ha/84 dias $(9 * 10 /(100))^{4}$ & 17,81 & 22,58 & 24,13 & 28,51 \\
\hline Produção de carne, @/ha/84 dias $(11 /(15))^{5}$ & 1,19 & 1,51 & 1,61 & 1,90 \\
\hline
\end{tabular}

Os dados permitem inferir que a intensificação do processo produtivo e o aumento do ganho médio diário dos animais elevaram o custo da arroba produzida $(\mathrm{P}<0,05)$, como resultado principalmente da adição do custo do concentrado, uma vez que as demais despesas que compuseram o custo total foram equivalentes em todos os tratamentos (Tabela 4). Em comparação ao grupo que recebeu sal mineral, aqueles sob suplementação apresentaram aumento de aproximadamente 252,80; 470,48 e $600,81 \%$ no custo da arroba produzida. A participação do suplemento na composição do custo total da arroba produzida representou $14,52 \%$ (sal mineral) e 75,78; 85,02 e 87,80\% (concentrado nos níveis de 0,3; 0,6 e 0,9\% do PV).
Há interrelação entre a viabilidade econômica do sistema de suplementação e o custo dos ingredientes do suplemento (Figueiredo et al., 2007). Os preços dos suplementos utilizados foram relativamente elevados, uma vez que em grande parte do estado da Bahia não há produção de grãos nas proximidades das regiões produtoras de gado de corte, o que eleva o preço do produto, devido principalmente ao transporte. Uma das alternativas para viabilizar a suplementação seria o uso de subprodutos regionais que comprovadamente possam ser utilizados em substituição parcial ou total aos alimentos tradicionais com a perspectiva de reduzir substancialmente o custo do suplemento.

Os resultados (Tabela 5) comprovam que a suplementação elevou a quantidade de arrobas produzidas

Tabela 4 - Custos operacionais utilizados na composição dos custos totais de produção

\begin{tabular}{|c|c|c|c|c|}
\hline Item & Sal mineral & \multicolumn{3}{|c|}{ Nível de suplementação (\% do peso vivo) } \\
\hline Produção de carne (@/ha/84 dias) & 1,19 & 1,51 & 1,61 & 1,90 \\
\hline Consumo de concentrado (kg/ha/84 dias) & - & 77,53 & 155,08 & 232,61 \\
\hline Consumo de mineral $(\mathrm{kg} / \mathrm{ha} / 84$ dias & 2,45 & - & - & - \\
\hline Preço estimado do concentrado ou sal mineral ( $\mathrm{R} \$ / \mathrm{kg})$ & 0,87 & 0,64 & 0,62 & 0,62 \\
\hline Custo com concentrado (R\$/@) (4/0) & - & 32,97 & 59,80 & 75,87 \\
\hline Custo com suplemento mineral (R\$/@) (5/0) & 1,79 & - & - & - \\
\hline Mão-de-obra (R\$/@ - ANUALPEC, 2006) & 4,00 & 4,00 & 4,00 & 4,00 \\
\hline Combustíveis (R\$/@ - ANUALPEC, 2006) & 2,05 & 2,05 & 2,05 & 2,05 \\
\hline Medicamentos (R\$/@ - ANUALPEC, 2006) & 0,73 & 0,73 & 0,73 & 0,73 \\
\hline Manutenção de cercas (R\$/@ - ANUALPEC, 2006) & 0,80 & 0,80 & 0,80 & 0,80 \\
\hline
\end{tabular}

${ }^{1} \hat{\mathrm{Y}}=15,79+83,0233 \mathrm{x}\left(\mathrm{r}^{2}=0,98\right)$. 
por hectare $(\mathrm{P}<0,05)$. Pressupõe-se que suplementação a pasto permite a programação dos ganhos de peso para que os animais possam ser comercializados em determinado momento em que a cotação da arroba esteja em um patamar favorável. Nesse sentido, a viabilização de um planejamento de vendas que possibilite a adoção dessa prática pode ter participação fundamental no resultado final da atividade.

Em comparação à suplementação com sal mineral, com o fornecimento de concentrado, a renda bruta, em R \$, obtida pela produção em cada hectare de terra aumentou em torno de 26,88\%(0,3\% PV); 35,29\%(0,6\% PV)e 59,66\%(0,9\% PV). No entanto, esse aumento foi inviabilizado economicamente pela elevação dos custos, de 252,80; 470,48 e 600,81\%, respectivamente, para a suplementação nos níveis de 0,3 ; 0,6 e $0,9 \%$ em comparação à oferta de sal mineral. Neste contexto, a suplementação em níveis superiores a $0,3 \%$ do peso vivo pode comprometer a taxa de retorno da atividade, reduzindo em 65,44\% o lucro por hectare nos 84 dias. Corrobora para essa informação a análise economica feita por Porto et al. (2009), que encontraram viabilidade econômica em suplementos com nível inferior a $0,3 \%$ do peso vivo. Nos níveis de suplementação a 0,6 e0,9\% do PV, houve prejuízo de $R$ \$24,38 e R \$59,30 reais, respectivamente, em comparação à oferta de sal mineral. A curva da produção em kg de carne por hectare por ano aumenta em taxas decrescentes $(\mathrm{P}<0,05)$ conforme aumentaram os níveis de suplementação, o que poderia apresentar resultados mais competitivos, caso houvesse uma elevação da carga animal por área, uma vez que a taxa de lotação utilizada foi de $0,67(0,66$ a 0,68) UA/ hectare. Segundo Figueiredo et al. (2007), baixas taxas de lotação refletem sistemas de baixa produção de peso vivo, o que obriga o produtor a sobreviver na marginalidade da cadeia produtiva com poucas condições de oferecer produtos com preços competitivos, quase sempre perdendo terras e mercado para agricultores e pecuaristas mais eficientes com sistemas ou culturas mais rentáveis.

Outro aspecto que compromete a viabilidade econômica dos sistemas intensivos para terminação de bovinos no estado da Bahia é o baixo preço pago pela arroba do boi gordo em comparação a outros estados, o que contribui para redução da renda bruta do produtor.

Os resultados do contraste entre receitas e despesas (Tabela 6) demonstram o decréscimo acentuado em todas as variáveis em função dos níveis de suplementação testados. Quando se analisa a receita líquida, levando-se em consideração todos os custos operacionais mais o custo de aplicação do capital investido para compra do boi magro,

Tabela 5 - Previsão da renda bruta, custo operacional total e saldo da atividade nos níveis de suplementação

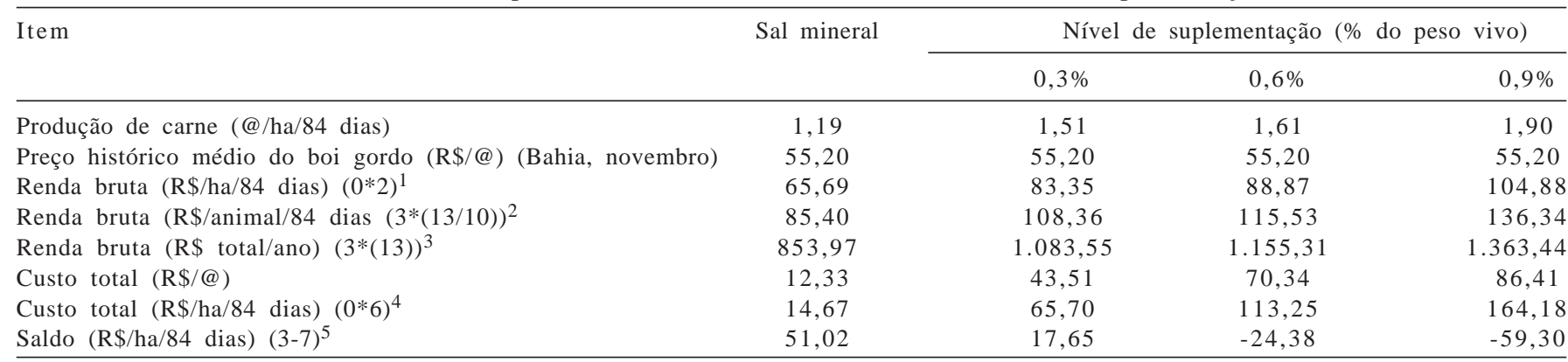

${ }^{1} \hat{Y}=67,23+41,030 \times\left(r^{2}=0,97\right) ;{ }^{2} \hat{Y}=87,41+53,330 \times\left(r^{2}=0,97\right) ;{ }^{3} \hat{Y}=874,04+533,390 x\left(r^{2}=0,97\right) ;{ }^{4} \hat{Y}=15,04+165,360 \times\left(r^{2}=0,99\right) ;{ }^{5} \hat{Y}=52,20-124,330 \times\left(r^{2}=0,99\right)$

Tabela 6 - Taxas de retorno obtidas com a atividade considerando todos os custos, o capital investido e os lucros obtidos com as estratégias de suplementação

\begin{tabular}{lccc}
\hline & Sal mineral & \multicolumn{2}{c}{ Nível de suplementação (\% PV) } \\
\cline { 3 - 4 } & & $0,3 \%$ & $0,6 \%$ \\
\hline Preço de aquisição do boi magro, R\$/@ & 52,00 & 52,00 \\
Compra do boi magro, R\$/ha/ano (ANUALPEC, 2006) & 494,40 & 52,00 & 52,00 \\
Custo operacional de produção, R\$/ha/84 dias & 14,67 & 494,40 & 494,40 \\
Capital investido, R\$/ha/84 dias (1+2) & 509,07 & 65,70 & 113,25 \\
Renda liquida com a atividade, R\$/ha/84 dias & 51,02 & 560,1 & 607,65 \\
Retorno da aplicação a 4\% ao ano, R\$ (3*(4\%/365*84) $)^{2}$ & 57,02 & 17,65 & $-24,38$ \\
Porcentagem total de retorno da atividade - $(4 / 3 *(100))^{3}$ & 10,02 & 62,73 & 68,06 \\
\hline
\end{tabular}

${ }^{1} \hat{Y}=509,44+165,360 x\left(r^{2}=0,99\right) ;{ }^{2} \hat{Y}=57,06+18,517 x\left(r^{2}=0,99\right) ;{ }^{3} \hat{Y}=9,67-21,407 x\left(r^{2}=0,99\right)$ 
obtém-se uma taxa de retorno decrescente, variando de 10,02 a -9,00\% em função dos níveis de suplementação com redução máxima observada entre a oferta de sal mineral e a suplementação com concentrado no nível de $0,9 \%$ do peso vivo (em torno de 200\%). Neste contexto, a oferta de sal mineral e a de concentrado no nível de $0,3 \%$ do PV seriam viáveis, principalmente pelo fato de que estudo foi desenvolvido em um ano cujos índices pluviométricos foram superiores à média histórica da região. Desta maneira, com uma estiagem mais rigorosa, o rendimento seria bem menor no grupo que recebeu apenas sal mineral, com manutenção ou pequeno decréscimo nos resultados obtidos com suplementação a $0,3 \%$ do peso vivo. Segundo Figueiredo et al. (2007), a maior precocidade dos sistemas de produção de carne bovina é alcançada somente se houver ajuste nutricional entre a oferta de forragem e a curva crescente de demanda do animal por nutrientes. Entretanto, o atendimento aos requisitos nutricionais do animal deve estar em consonância com o aspecto econômico, com a finalidade de garantir o desenvolvimento de sistemas que sejam auto-sustentáveis.

A taxa de retorno mensal da atividade foi de $3,58 \%$ para o grupo que recebeu sal mineral e de 1,13; -1,43 e -3,21\%, respectivamente, para os grupos sob suplementação nos níveis 0,$3 ; 0,6$ e $0,9 \%$ do peso vivo. A taxa de remuneração mensal com o fornecimento de sal mineral é maior e aquela obtida com o fornecimento de concentrado a $0,6 \%$ do peso vivo é inferior aos valores relatados por Fernandes et al. (2007), que alimentaram animais da raça Canchim em confinamento e encontraram taxa de retorno mensal de $1,86 \%$. A remuneração da poupança, quando considerados todos os custos, equivale ao retorno da suplementação com sal mineral.

Como a suplementação foi feita apenas na fase de terminação, os efeitos não ficaram tão evidentes, o que poderia ocorrer caso tivesse sido iniciada desde a recria dos amimais. Segundo Figueiredo et al. (2007), esse efeito estaria relacionado à redução da eficiência alimentar com o aumento da maturidade do animal.

\section{Conclusões}

O ganho de peso de animais sob suplementação apenas com sal mineral no período seco frequentemente apresenta valor negativo, nesse caso, há inversão na tendência de retorno financeiro em comparação a níveis de até $0,3 \%$ do peso vivo e até mesmo a níveis mais elevados, uma vez que o animal perderá peso e permanecerá mais tempo até ser abatido, imobilizando capital.

\section{Agradecimentos}

Ao CNPq e à FAPESB, pela concessão das bolsas de estudos, e ao Banco do Nordeste do Brasil, pelo apoio financeiro ao projeto.

\section{Referências}

ANUALPEC 2006. Anuário da pecuária brasileira. São Paulo: FNP Consultoria e Comércio, 2006. 364p.

CAMPBELL, A.G. Grazed pastures parameters: I. Pasture dry matter production and availability in a stocking rate and grazing management experiment with dairy cows. Journal Agricultural Science, v.67, n.2, p.211-216, 1966.

EUCLIDES FILHO, K. O enfoque de cadeia produtiva como estratégia para a produção sustentável de carne bovina. In: REUNIÃO ANUAL SOCIEDADE BRASILEIRA DE ZOOTECNIA, 28. 2004, Campo Grande. Anais... Campo Grande: Sociedade Brasileira de Zootecnia, 2004. p.568.

FERNANDES, A.R.M.; SAMPAIO, A.A.M.; HENRIQUE, W. et al. Avaliação econômica e desempenho de machos e fêmeas Canchim em confinamento alimentados com dietas à base de silagem de milho e concentrado ou cana-de-açúcar e concentrado contendo grãos de girassol. Revista Brasileira de Zootecnia, v.36, n.4, p.855-864, 2007.

FIGUEIREDO, D.M.; OLIVEIRA, A.S.; SALES, M.F.L. et al. Análise econômica de quatro estratégias de suplementação para recria e engorda de bovinos em sistema pasto-suplemento. Revista Brasileira de Zootecnia, v.36, n.5, p.1443-1453, 2007.

GARDNER, A.L. Técnicas de pesquisa em pastagens e aplicabilidade de resultados em sistemas de produção. Brasília: II CA/EMBRAPA-CNPGL, 1986. 197p. (II CA, Série publicações Miscelâneas, 634).

JORGE, A.M.; FONTES, C.A.A.; FREITAS, J.A. et al. Ganho de peso e de carcaça, consumo e conversão alimentar de bovinos e bubalinos, abatidos em dois estágios de maturidade. Revista Brasileira de Zootecnia, v.26, n.4, p.806-812, 1997.

McMENIMAN, N.P. Methods of estimating intake of grazing animals. In: REUNIÃO ANUAL DA SOCIEDADE BRASILEIRA DE ZOOTECNIA, 34., Juiz de Fora, 1997. Anais... Juiz de Fora: Sociedade Brasileira de Zootecnia, 1997. p.131-168.

NATIONAL RESEARCH COUNCIL - NRC. Nutrient requirements of beef cattle. 7.ed.rev. Washington, D.C.: National Academy Press, 2000. 242p.

NOGUEIRA, M.P. Viabilidade na adoção de tecnologia. In: Gestão Competitiva para a Pecuária, 2003, Jaboticabal. Anais... Jaboticabal: UNESP, 2003. p.4-32.

PILAU, A.; ROCHA, M.G.; SANTOS, D.T. Análise econômica de sistemas de produção para recria de bezerras de corte. Revista Brasileira de Zootecnia, v.32, n.4, p.966-976, 2003.

PORTO, M.O.; PAULINO, M.F.; VALADARES FILHO, S.C. et al. Fontes suplementares de proteína para novilhos mestiços em recria em pastagens de capim-braquiária no período das águas: desempenho produtivo e econômico. Revista Brasileira de Zootecnia, v.38, n.8, p.1553-1560, 2009.

SILVA, F.F.; SÁ, J.F.; SCHIO, A.R. et al. Suplementação a pasto: disponibilidade e qualidade $\mathrm{x}$ níveis de suplementação $\mathrm{x}$ desempenho. Revista Brasileira de Zootecnia, v.38, p.371-389, 2009 (supl. especial).

WILLIAMS, C.D.H.; DAVID, D.J.; IISMAA, J. The determination of cromic oxide in faeces samples by atomic absorption spectrophotometry. Journal of Agricultural Science, v.59, p.381-385, 1962.

WILM, H.G.; COSTELLO, D.F.; KLIPPLE, G.E. et al. Estimating forage yield by the double sampling method. Journal of American Society of Agronomy, v.36, p.194-203, 1994. 